D.O.I: $10.3895 / \mathrm{S} 1808-04482013000100008$

\title{
ANÁLISE DA QUALIDADE DOS SERVIÇOS EM UMA ESCOLA PÚBLICA UTILIZANDO A FERRAMENTA SERVPERF
}

\section{SAMPLE PAPER TO BE USED AS MODEL TO FORMAT THE ARTICLES TO BE SUBMITTED TO THE INDUSTRIAL MANAGEMENT MAGAZINE}

\author{
Eunice Alves de Oliveira ${ }^{1}$; Gislaine Camila Lapasini Leal ${ }^{2}$; Francielle Cristina Fenerich ${ }^{3}$ \\ ${ }^{1}$ Universidade Estadual de Maringá - UEM - Maringá - Brasil \\ eunice_viega@hotmail.com \\ ${ }^{2}$ Universidade Estadual de Maringá - UEM - Maringá - Brasil \\ gclleal@uem.br \\ ${ }^{3}$ Universidade Estadual de Maringá - UEM - Maringá - Brasil \\ fcfenerich@uem.br
}

\begin{abstract}
Resumo
A satisfação das necessidades dos consumidores de órgãos públicos é muito difícil de ser encontrada devido às características peculiares dos serviços. Com base nessa preocupação, o presente trabalho tem por finalidade diagnosticar a qualidade dos serviços de atendimento ao público ofertado pela equipe de secretaria de uma escola pública do município de Maringá, Estado do Paraná. Para avaliar o nível de satisfação e descobrir os pontos fortes e fracos da instituição foi utilizada a ferramenta de aferição da qualidade SERVPERF que sofreu algumas adaptações da versão original. Na coleta de dados foi elaborado um questionário com 20 indicadores, dividida em cinco dimensões da qualidade sendo: aspectos tangíveis, confiabilidade, prontidão, segurança e empatia, o respondente indicou seu nível de concordância em cada quesito. A confiabilidade do questionário foi identificada através do Coeficiente de Cronbach atingindo nível excelente. Os resultados obtidos foram apresentados aos interessados para servir de base na tomada de decisão.
\end{abstract}

Palavras-chave: qualidade de serviços; instituição pública; SERVPERF.

\section{Introdução}

A prestação de serviços é algo muito subjetivo e difícil de definir. A reputação dos serviços prestados depende totalmente de como o indivíduo se sente ao ser atendido, o estado de espírito, a cultura e o momento afetam a maneira como o serviço é percebido.

Segundo Gianesi e Corrêa (1994, p. 32) os serviços são experiências que o cliente vivencia enquanto que os produtos são coisas que podem ser possuídas. A intangibilidade dos serviços é que dificulta avaliar o resultado e a qualidade do mesmo. 
Nesse sentido, tem-se que a qualidade na prestação de serviços não é fácil de ser alcançada, mas é compensatória, sendo essencial ao perfeito funcionamento de qualquer empresa prestadora de serviços.

A qualidade dos serviços está diretamente relacionada à plena satisfação do cliente. Para que isso aconteça, o segredo é concentrar-se nas necessidades e desejos do cliente oferecendo um serviço que atenda ou exceda suas expectativas. A satisfação das necessidades dos consumidores de órgãos públicos é mais difícil de ser encontrada devido às características peculiares dos serviços. Seu caráter intangível dificulta testes e medidas antes deste ser ofertado e, cada oferta de serviço é única se comparada com a anterior. Enquanto os produtos satisfazem as necessidades dos consumidores através de suas características físicas e tangíveis, a produção de serviços exige mais dos recursos humanos, da organização e dos próprios consumidores de tal serviço. Tais diferenças geram heterogeneidade na composição dos serviços e, em média, um baixo desempenho.

Esse trabalho tem por objetivo avaliar a qualidade da prestação do serviço oferecido pela equipe de funcionários da secretaria de uma Escola Pública de Maringá que oferta a Educação Básica na Modalidade de Ensino Fundamental. A ferramenta utilizada para diagnosticar qual o nível de satisfação dos pais foi a SERVPERF. Com base nesta análise foi possível conhecer os pontos fortes e fracos e quais os indicadores passivos de melhorias. O trabalho foi apresentado para a equipe administrativa local para que esta com base no estudo busque soluções que venham a melhorar os pontos fracos. O presente trabalho se justifica pela necessidade de um levantamento do nível de satisfação dos usuários, mais especificamente, dos pais, para obtenção de informações relativas à qualidade dos serviços que venham a auxiliar a equipe administrativa local na tomada de decisões.

\section{Revisão de Literatura}

\subsection{Qualidades em Serviços}

O processo de geração de serviços envolve a produção de bens intangíveis. Sendo o serviço sempre uma ação desenvolvida por terceiros, em atendimento a solicitação explícita, específica e bem definida de determinado usuário. Na maioria das vezes, esses terceiros habilitam-se a realizar o serviço por estarem qualificados para tanto (PALADINI, 2006, p. 186).

Segundo Gianesi e Corrêa (1994, p. 32) os serviços são experiências que o cliente vivencia enquanto que os produtos são coisas que podem ser possuídas. A intangibilidade dos serviços é que dificulta avaliar o resultado e a qualidade do mesmo.

Martins (2005, p. 436) aborda que as principais características dos serviços são: i) alto contato com o cliente; participação do cliente no processo; não estocável; mão de obra intensiva; 
curto lead time; output variável e não padronizável; intagibilidade; dificuldade em mensurar produtividade e qualidade.

Denis Walker (1991, p. 39) destaca que a qualidade dos serviços depende muito do fato de as pessoas que estão realizando sentirem-se bem em relação a si mesmas. Uma vez que, a imagem e reputação são criadas e arruinadas, de acordo com o desempenho dos funcionários que lidam diretamente com o cliente.

Nesse sentido, capacitar o funcionário que prestam serviços torna-se tão importante quanto como fazemos com os itens materiais. De acordo com Nascimento (2003), a qualidade de um produto ou serviço é obtida por meio do atendimento perfeito, de forma confiável, de forma acessível, de forma segura e no tempo certo às necessidades do cliente, ou seja, a qualidade de um produto ou serviço é medida pela satisfação total do consumidor. O conceito de qualidade está sempre em equilíbrio entre estes fatores: qualidade intrínseca do produto ou serviço, custo e atendimento (quantidade certa, local certo, hora certa).

Albrecht e Bradford apud Coutinho, Moreira e Souza (2005) mostram que um ciclo de serviço é um mapa dos momentos da verdade, conforme vivenciado pelo cliente sendo ativado cada vez que um cliente entra em contato com a empresa. O mapeamento dos ciclos de serviços para os vários aspectos da organização é importante, uma vez que através dessa técnica pode-se enxergar a empresa pelo ângulo do cliente.

Em Las Casas (1999) tem-se que as dimensões da qualidade mais específicas para o setor de serviço são:

- Confiança: habilidade de prestar o serviço solicitado, de forma precisa e segura;

- Receptividade: disposição para ajudar os clientes;

- Segurança: conhecimento e cortesia dos funcionários e sua habilidade em demonstrar confiança;

- Aspectos tangíveis: aspectos físicos que envolvem a atividade de prestação de serviços, como instalações, equipamentos e aparência dos funcionários;

- Empatia: grau de cuidado e atenção pessoal oferecido aos clientes.

A área de prestação de serviços envolve a produção de serviços propriamente ditos. Ao contrário da indústria, não existe a possibilidade de separação, com nitidez, do processo produtivo da prestação de serviço - ambos se confundem. Nesse sentido, no ambiente de prestação de serviços a qualidade centra-se fundamentalmente na interação com o usuário, sendo nesse processo interativo que a qualidade aparece.

Para atingir a satisfação dos clientes, é necessário, portanto, que as empresas busquem conhecer sua satisfação ou insatisfação. Um dos mecanismos para manter a satisfação dos clientes, 
mesmo quando estes apresentam defeitos, é a velocidade com que as empresas respondem aos problemas decorrentes da má qualidade de produtos ou serviços (MIGUEL, 2001, p. 254).

Dessa forma, se o serviço prestado excede ou atende a expectativa do cliente, ele tem a percepção de que este foi prestado com qualidade. Caso contrário, ele terá a percepção de que o serviço não possui qualidade. Portanto, se estas forem atendidas a qualidade será satisfatória; se as expectativas não forem atendidas a qualidade é inaceitável, mas, se as expectativas dos clientes forem excedidas, ou melhor, ele receber mais do que tinha planejado a qualidade é total.

Quatro fatores podem influenciar as expectativas do cliente: comunicação boca a boca, necessidade pessoais, experiências passadas e comunicação externa estas indicarão qual será a expectativa do cliente em relação ao serviço, sendo que, a comunicação boca a boca é um dos fatores mais importante na formação da expectativa do cliente (GIANESI e CORRÊA, 1994, p. 82).

Os serviços prestados estão sempre sendo avaliados, mesmo que inconscientemente, pelos clientes. Quando alguém entra em um cinema, observa de imediato o ambiente físico, se é limpo, se a temperatura é adequada, se as poltronas são confortáveis, para depois, avaliar os aspectos específicos do serviço. Existem ainda outros aspectos que são observados, como, o uso dos banheiros, como são as instalações e a limpeza. Nesse sentido, um cliente interage com um ambiente físico, processos e indivíduos, o que resulta numa percepção de todos esses aspectos situacionais, conduzindo a um julgamento em que decide se a experiência foi boa ou não. Quando o serviço prestado atinge a satisfação, é então considerado de boa qualidade (MIGUEL, 2001, p. 48).

As necessidades pessoais, experiências passadas e a propaganda boca a boca indicarão qual será a expectativa do cliente em relação ao serviço; a empresa tem em seu âmbito de trabalho as dimensões da qualidade que irão auxiliá-la a prestar um serviço que atenda ou supere as expectativas dos clientes. Diante da importância dos fatores ou dimensões genéricas que contribuem para qualidade do serviço, os dez fatores serão apresentados e explicados, conforme Parasuraman, Zithaml e Berry apud Ferreira (2005, p. 10), sendo eles:

- Tangibilidade: Refere-se às evidências físicas do serviço;

- Confiabilidade: A confiabilidade relaciona-se à consistência do serviço.

- Receptividade: Refere-se à disposição e/ou prontidão dos funcionários para prestar um serviço;

- Competência: A competência está relacionada às habilidades e ao conhecimento dos trabalhadores para realizar um serviço adequadamente;

- Cortesia: Refere-se à polidez, ao respeito, à consideração e ao comportamento amigável do pessoal que está em contato com os clientes; 
- Credibilidade: A credibilidade refere-se às características de confiança, possibilidade de acreditar e honestidade do trabalhador que presta o serviço;

- Segurança: A segurança refere-se à isenção de qualquer perigo, risco ou problema;

- Acesso: Refere-se à acessibilidade e a facilidade de contato;

- Comunicação: Refere-se à capacidade da empresa prestadora de serviços manter comunicação eficaz com seus clientes;

- Compreensão e respeito do cliente: Refere-se ao esforço realizado pelo trabalhador que realiza o serviço para atender as necessidades específicas de cada cliente.

Das dez dimensões citadas como fatores fundamentais para o alcance da qualidade na prestação dos serviços pelas empresas, oito estão relacionadas aos trabalhadores. Estes, portanto, são os responsáveis diretos pela qualidade do serviço prestado.

\title{
2.2 Qualidade dos Serviços Públicos
}

A qualidade dos serviços públicos tem a ver com o retorno esperado pela sociedade do investimento realizado por meio do pagamento de taxas, impostos, entre outros. Assim, deve haver um equilíbrio entre os recursos investidos e os benefícios recebidos pela comunidade.

\begin{abstract}
Serviços públicos são serviços fornecidos à comunidade pelo Estado, aos quais por princípio, todo cidadão tem direito. Abrangem todos os serviços prestados pelo aparelho burocrático-administrativo dos governos e o conjunto de benefícios que o Estado é obrigado por lei a prestar à população em áreas como educação, saúde, previdência social, saneamento básico e lazer (MENDES FILHO, 1997, p. 36).
\end{abstract}

Habitualmente quem paga pela prestação de serviço é o cliente. Nos serviços públicos, o governo faz a intermediação do pagamento que é efetivamente pago pelo povo, o cidadão (MENDES FILHO, 1997, p. 35).

Para que os serviços públicos possam ter qualidade é essencial que eles tenham competidores de mercado. Os serviços públicos, não importando a sua área de atuação, devem atender aos requisitos previstos na Constituição da República, sendo eles a legalidade, moralidade, impessoalidade, publicidade e a finalidade que tem por objetivo nada mais do que, o atendimento do interesse público (MENDES FILHO, 1997, p. 38).

Os órgãos públicos devem possuir qualidade e produtividade com nível internacional, para atingir a satisfação de qualquer pessoa, independente de sua origem, raça, religião, costume diante da globalização da economia e da integração dos países. Para que isso seja possível em Mendes Filho (1997, p. 107) temos as diretrizes de qualidade e produtividade que os serviços públicos devem elaborar e seguir, quais sejam: criar conselho de qualidade e produtividade, para o acompanhamento e desenvolvimento de políticas e estratégias apropriadas; criar comissões de qualidade e produtividade setoriais, para executarem as deliberações do Conselho; instituir 
programa de educação e treinamento para todos os funcionários públicos, para desenvolveram suas respectivas funções; buscar a satisfação de todos os usuários, internos e externos dos serviços públicos, como também dos seus fornecedores; criar indicadores de desempenho para acompanhamento de resultados; elaborar planejamento estratégico a curto médio e longo prazo, com a participação de todos os envolvidos; desenvolver gestão democrática, com delegação de autoridade e responsabilidade para cada gestor de processo; criar instrumentos de avaliação do desempenho profissional, com reconhecimento e estímulo à melhoria constante; participar de avaliações externas do nível da qualidade e produtividade da organização através de prêmios, certificações e outros instrumentos de reconhecimento; e, engajar a instituição em ações de desenvolvimento integrado com a comunidade onde está situada.

De acordo com Normando (2009) os fundamentos da nova administração pública voltada para o cidadão revelam que, se a qualidade dos serviços de uma organização depende da satisfação do usuário, então, o seu atendimento deve ser sempre o melhor possível, fazendo com que haja um diferencial qualitativo substancial. Para isso, é necessário adotar ações inovadoras capazes de mobilizar todos os recursos disponíveis em busca de soluções eficientes e eficazes, dentro do processo de trabalho das organizações públicas.

No entanto, como mensurar a qualidade dos serviços oferecidos ao cidadão? A resposta está na satisfação dos usuários. Usuário satisfeito é garantia de boa qualidade nos serviços prestados pelas organizações. Assim, quanto maior a satisfação do usuário melhor é a qualidade do atendimento e cumprimento das expectativas do público. É importante frisar que, os padrões de bons serviços aos cidadãos devem ser obtidos com os próprios usuários.

\section{Método de Pesquisa}

Este trabalho se caracteriza como uma pesquisa aplicada, em relação à natureza; quantitativa, quanto à abordagem; e no que se refere aos objetivos caracteriza-se como descritiva, pois visa relatar as características de determinada população ou fenômeno e envolve o uso de técnicas padronizadas de coleta de dados (GIL, 1991). As etapas conduzidas na elaboração desta pesquisa foram: Planejamento, Teste Piloto, Coleta de Dados e Análise dos Resultados.

\subsection{Planejamento}

Esta etapa foi composta pelas seguintes atividades: seleção dos participantes, seleção do método e elaboração do instrumento de pesquisa.

- Seleção dos Participantes: todos os pais de alunos matriculados na escola foram convidados a participar do estudo. 
- Seleção do Método: nesta etapa foram conduzidos estudos sobre as ferramentas SERVQUAL e SERVPERF. O método SERVPERF foi selecionado primeiramente pela vantagem de utilizar metade das questões que seriam necessárias para aplicação do modelo descartado, segundo pela simplificação de forma significativa da aplicação do questionário, não prejudicando o resultado da pesquisa (CRONIN e TAYLOR, 1992).

- Elaboração do instrumento de pesquisa: o instrumento de pesquisa elaborado foi um questionário estruturado com base no método SERVPERF, ou seja, apenas as questões relacionadas a percepção do cliente foram consideradas, excluindo aquelas que remetem a avaliação das expectativas. O questionário foi adaptado, contendo 20 afirmações onde da as questão de 1 a 4 eram referentes aos aspectos tangíveis, as questões de 5 a 8 relacionadas à confiabilidade, as questões de 9 a 12 referentes à prontidão, as questões de 13 a 16 referentes à segurança e por fimm as questões de 17 a 20 relacionadas à empatia. Foi utilizada empregada uma escala Likert de 5 pontos que varia de (1) discordo totalmente até (5) concordo totalmente.

\subsection{Teste Piloto}

Com o objetivo de identificar e eliminar problemas potenciais no instrumento de pesquisa foi realizado um teste piloto, em que foram aplicados 15 questionários aos pais que utilizaram o serviço de atendimento no período de 15 a 19 de agosto de 2011. Após responder o questionário os pais foram questionados quanto ao entendimento do mesmo. O teste piloto permitiu analisar se as questões eram claras e não ambíguas. Após essa etapa verificou-se que o questionário não apresentava dificuldade de compreensão pelos respondentes, não havendo necessidade de realizar adequações.

\subsection{Coleta de Dados}

O questionário foi aplicado no período de 29 de agosto a 16 de setembro de 2011, sendo enviado aos pais um total de 301 questionários por meio dos alunos da instituição que também foram responsáveis pelo retorno do mesmo. Do total de 301 questionários enviados aos pais, obteve-se um retorno de 182 destes, ou seja, $60 \%$ do total enviado.

\subsection{Análise dos Resultados}

Após a aplicação do questionário foram aplicadas técnicas de estatística descritiva, pois como os valores estão em escala ordinal é possível aplicar medidas de tendência central (moda e mediana) para destacar os acontecimentos e melhorar a compreensão sobre o conjunto de dados. 


\section{Análise dos Resultados}

Entre os 182 participantes da pesquisa, a média de idade calculada foi de 38 anos e 8 meses, $74 \%$ dos respondentes são do sexo feminino, confirmando a predominância da mãe ou o questionáriodo sexo feminino como responsáveis pelo acompanhamento da educação das crianças, no sexo masculino temos $26 \%$ dos respondentes um valor muito abaixo do percentual alcançado pelo sexo feminino

A Tabela 1 apresenta a média e a variância dos dados obtidos para cada uma das dimensões da qualidade. A partir desses dados é possível verificar o modo como cada dimensão foi avaliada e quais necessitam de mudanças para que se alcance a satisfação dos pais.

Tabela 1 - Média e Variância para cada indicador de qualidade.

\begin{tabular}{|c|c|c|c|}
\hline Dimensão & Indicadores da qualidade & Média & Variância \\
\hline \multirow{4}{*}{ 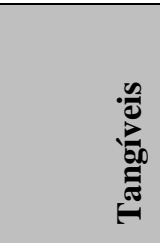 } & $\begin{array}{l}1 \text { A Escola possui equipamentos modernos como computadores, } \\
\text { impressoras e internet }\end{array}$ & 4,1 & 1,36 \\
\hline & As instalações físicas da Escola são de boa aparência & 3,5 & 1,86 \\
\hline & A localização da Escola é de fácil acesso & 4,6 & 0,90 \\
\hline & $\begin{array}{l}\text { Os Funcionários da Escola se apresentam com roupas adequadas e } \\
\text { boa aparência }\end{array}$ & 4,4 & 0,94 \\
\hline \multirow{4}{*}{ 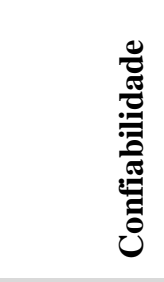 } & $\begin{array}{l}\text { Quando um pai tem um problema, os Funcionários da Escola } \\
\text { demonstram um sincero interesse em resolvê-lo }\end{array}$ & 4,1 & 1,44 \\
\hline & $\begin{array}{l}\text { Os Funcionários da Escola executam seus serviços em tempo } \\
\text { adequado }\end{array}$ & 4,3 & 0,95 \\
\hline & O atendimento dos Funcionários da Escola transmite confiança & 4,3 & 1,11 \\
\hline & $\begin{array}{l}\text { Os Funcionários da Escola realizam o serviço certo da primeira vez e } \\
\text { persiste na sua execução sem erros. }\end{array}$ & 4,0 & 1,13 \\
\hline \multirow{4}{*}{ مِ } & $\begin{array}{l}\text { Os Funcionários da Escola possuem os conhecimentos necessários } \\
\text { para atendê-lo }\end{array}$ & 4,3 & 0,85 \\
\hline & $\begin{array}{l}\text { Os Funcionários da Escola estão focados em prestar o melhor serviço } \\
\text { aos pais }\end{array}$ & 4,2 & 1,10 \\
\hline & $\begin{array}{l}\text { Os Funcionários da Escola estão sempre dispostos em ajudar a } \\
\text { solucionar seus problemas }\end{array}$ & 4,3 & 1,08 \\
\hline & $\begin{array}{l}\text { Os Funcionários da Escola disponibilizam-se a ajudar os pais de } \\
\text { imediato }\end{array}$ & 4,2 & 1,15 \\
\hline \multirow{4}{*}{ 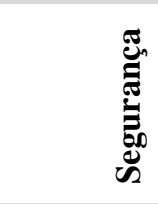 } & Você pode acreditar nos Funcionários da Escola & 4,2 & 1,22 \\
\hline & Os Funcionários da Escola demonstram segurança no atendimento & 4,3 & 1,01 \\
\hline & Os Funcionários da Escola são educados & 4,3 & 1,07 \\
\hline & $\begin{array}{l}\text { Os Funcionários da Escola possuem suporte adequado para atender } \\
\text { seus clientes }\end{array}$ & 4,2 & 0,97 \\
\hline \multirow{4}{*}{ 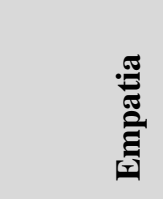 } & Os Funcionários da Escola prestam atendimento personalizado & 3,8 & 1,52 \\
\hline & A Escola possui horário de atendimento adequado & 4,2 & 1,57 \\
\hline & $\begin{array}{l}\text { Os Funcionários da Escola compreendem suas necessidades } \\
\text { específicas }\end{array}$ & 4,1 & 1,28 \\
\hline & O contato realizado com a Escola através do telefone é eficiente & 4,4 & 0,94 \\
\hline
\end{tabular}

É possível observar, por meio da análise da Tabela 1, que com exceção dos indicadores 2 e 17 os demais obtiveram uma ponderação ótima, pois apresentaram valores acima da média 4. Deste modo, pode-se concluir que os serviços prestados pelos colaboradores da secretaria da instituição aos pais dos alunos é satisfatório. Em relação ao indicador 2 (As instalações físicas da Escola são de boa aparência) que faz parte do grupo de indicadores da dimensão dos aspectos tangíveis que 
alcançou uma média de 3,5 e ao indicador 17 (Os Funcionários da Escola prestam atendimento personalizado), que pertence ao grupo relacionado à empatia, é importante que os responsáveis pela Administração da Instituição deem atenção especial para melhorar esses índices definindo estratégias que possam sanar estas deficiências e melhorar a percepção da qualidade.

Ainda em relação ao indicador 2 , aspectos tangíveis, é importante ressaltar que a escola depende da liberação de verbas do governo, e que esta é uma dificuldade da Administração local, que já possui até projeto em andamento, como exemplo, o de cobertura da quadra esportiva, mas como depende de aprovação por órgãos do Estado (SEED), este processo pode levar tempo para ser implementado.

No que se refere ao indicador 17 , relativo ao aspecto empatia, uma alternativa seria a capacitação contínua dos funcionários, que também depende de cursos ofertados pelo governo. Nos últimos anos percebe-se que isso vem ocorrendo de forma mais constante.

As dimensões confiabilidade, prontidão e segurança obtiveram médias acima de quatro, demonstrando que os pais estão satisfeitos com esses aspectos. A partir da análise dos resultados, pode-se concluir que em relação à execução do trabalho pelos funcionários em tempo adequado, de forma correta e com conhecimento, confiabilidade; disponibilidade dos funcionários em atender as necessidades dos pais, prontidão; a confiança que os funcionários transmitem no atendimento ao público, segurança. A instituição deve continuar investindo para manter ou até melhorar esses indicadores. Vale ressaltar que esses indicadores só obtiveram uma média boa devido à atenção da Equipe Administrativa da instituição em reconhecer que para que se alcance uma educação com qualidade se faz necessário investir em todos os setores, sendo o atendimento ao público uma delas.

A Tabela 2 sumariza os resultados apresentando a média obtida para cada dimensão da qualidade.

Tabela 2 - Média obtida em cada dimensão da qualidade.

\begin{tabular}{lc}
\hline Dimensão & Média \\
\hline Aspectos Tangíveis & 4,2 \\
Confiabilidade & 4,2 \\
Prontidão & 4,3 \\
Segurança & 4,3 \\
Empatia & 4,1 \\
\hline
\end{tabular}

Ao analisar a Tabela 2 verifica-se que a instituição pesquisada atingiu uma boa média em todas as dimensões. Para melhor visualizar a frequência das respostas dos indicadores do questionário nas Figuras 1, 2, 3, 4 e 5 são apresentadas as informações relativas a frequência dos indicadores por dimensão, sendo elas: aspectos tangíveis, confiabilidade, prontidão, segurança e empatia. 
Na Figura 1, que aborda a dimensão Aspectos Tangíveis, é possível verificar que nos quatro indicadores dessa dimensão a frequência maior foi em relação à opção 5 - Concordo Totalmente. Vale frisar que na questão 2 que trata da aparência física da escola é foi encontrado o maior grau de insatisfação dos pais, onde a maioria optou por resposta a opção 4 - Concordo Parcialmente, revelando que nesse aspecto devem ser tomadas medidas que venham a melhorar este indicador.

Figura 1- Frequência da Dimensão Aspectos Tangíveis.

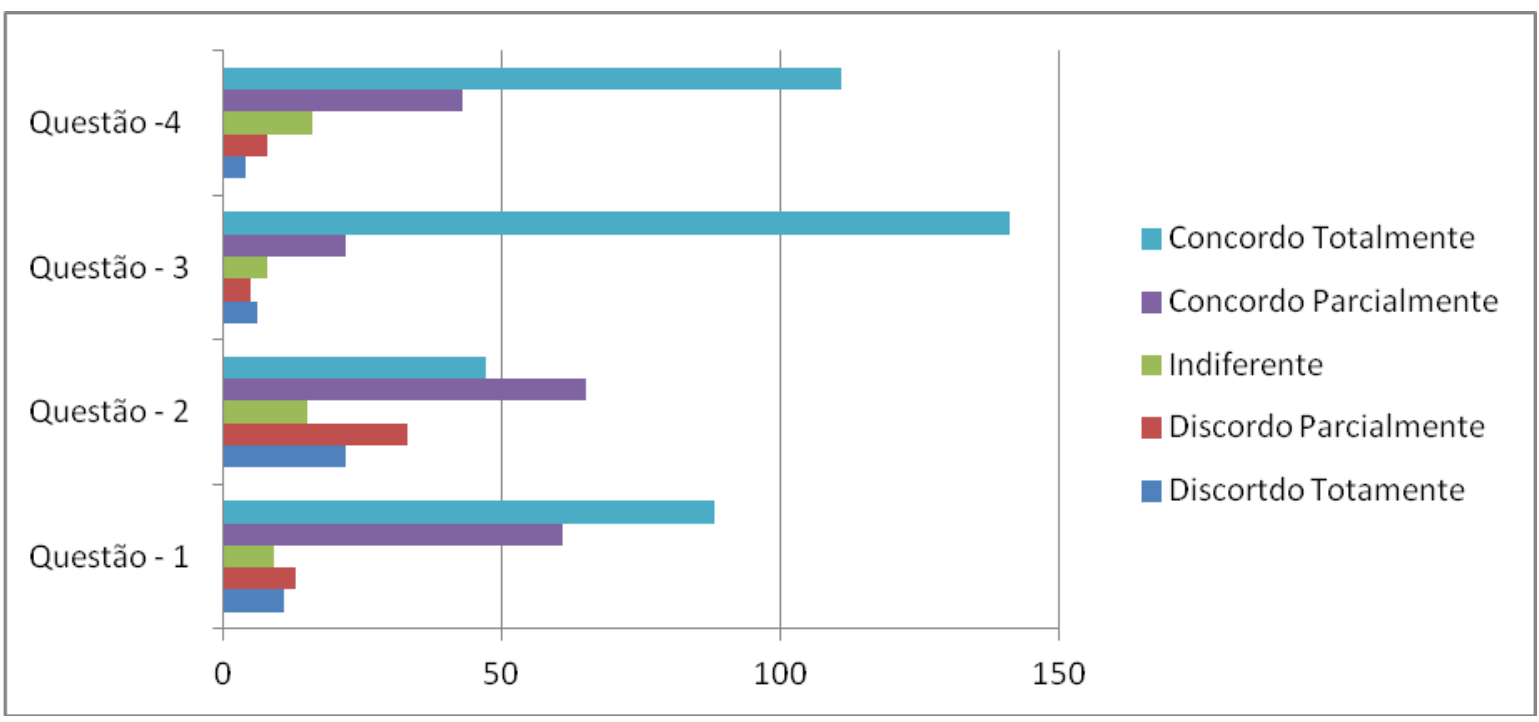

No que se refere a dimensão Confiabilidade (Figura 2) é possível verificar que a maioria dos pais aprova e confia no atendimento recebido pelos colaboradores da secretaria da instituição.

Figura 2 - Frequência da Dimensão Confiabilidade.

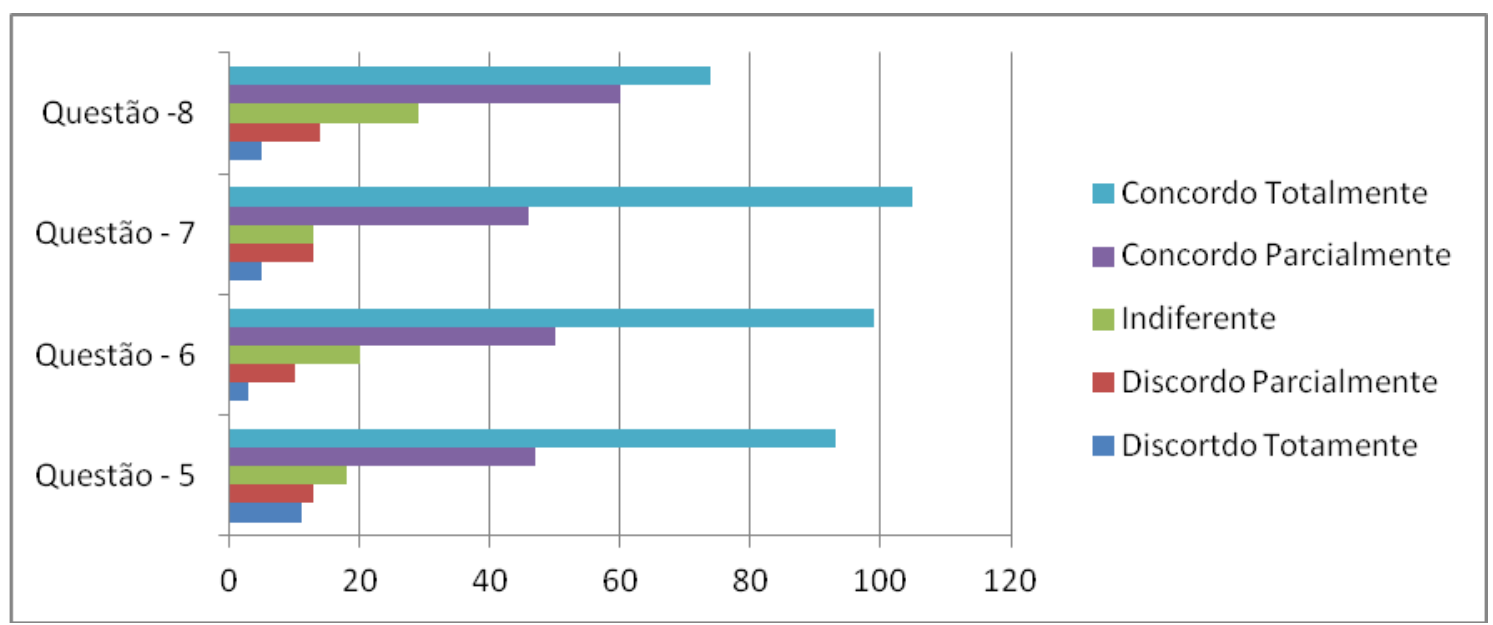

A Figura 3 apresenta a frequência dos resultados obtidos para a dimensão prontidão, que trata da capacidade de resposta, disposição e preparo dos funcionários. A partir da análise dos indicadores é possível que a maioria dos pais estão satisfeitos com esse aspecto. 
Figura 3 - Frequência da Dimensão Prontidão.

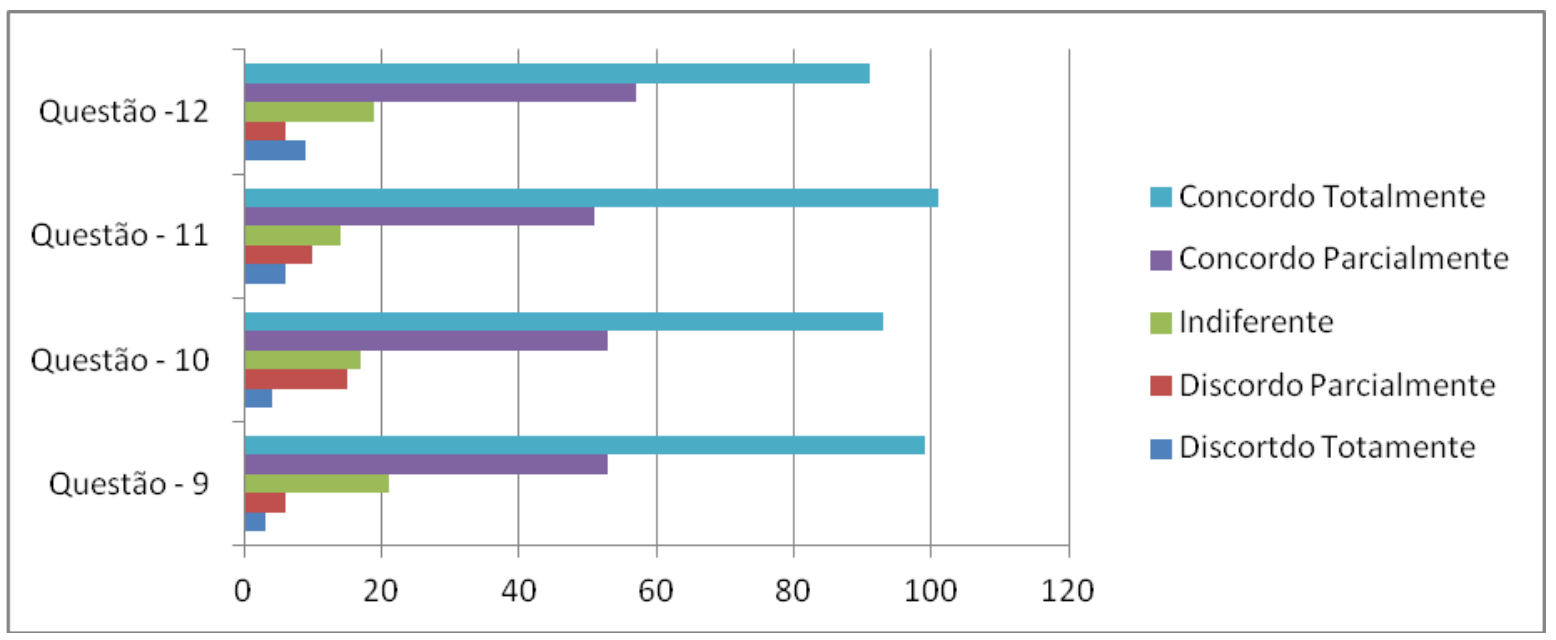

Na Figura 4 tem-se a distribuição de frequências para a dimensão Segurança., que refere-se a capacidade dos funcionários em transmitir segurança, ou seja, na competência, educação, cortesia e precisão. Analisando os dados é possível verificar a aprovação dessa dimensão pelos pais. No entanto, destaca-se que na questão 16 , que trata do suporte necessário ao atendimento, verifica-se que houve maior variação, servindo como alerta para que a Equipe Administrativa local possa buscar melhorias para este indicador.

Figura 4 - Frequência da Dimensão Segurança.

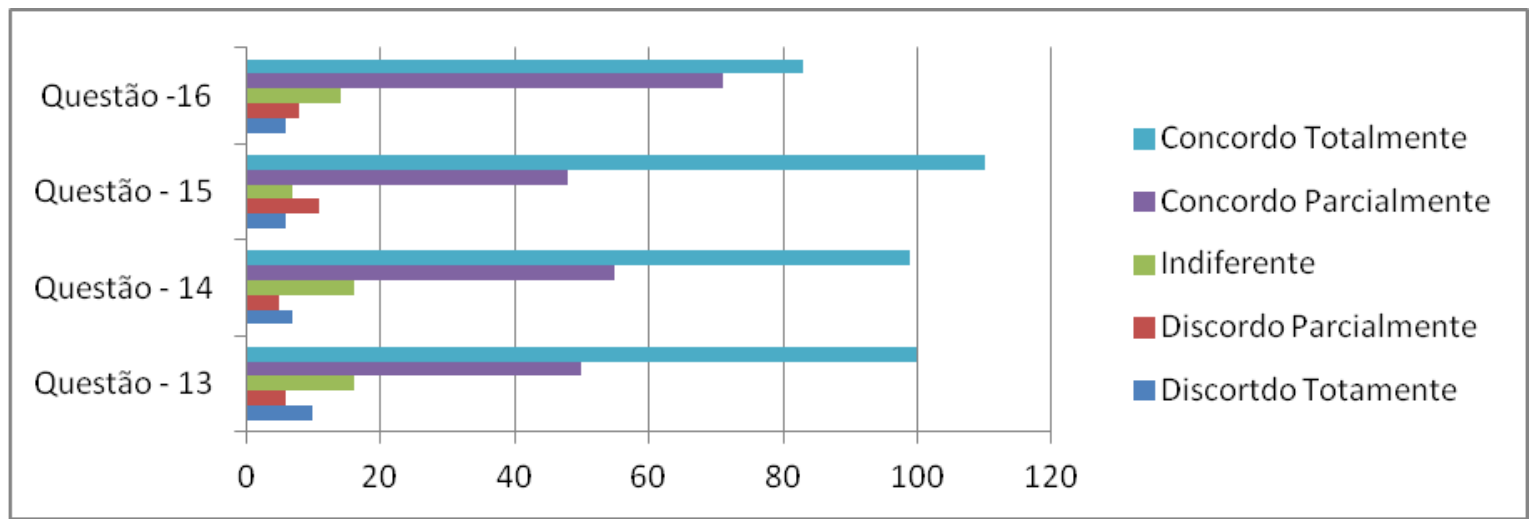

A dimensão Empatia (Figura 5) refere-se ao esforço empreendido pelos colaboradores para compreender as necessidades dos pais, ou seja, é o fornecimento de atenção individualizada é o colocar-se no lugar do outro. Verifica-se nessa dimensão a aprovação por parte da maioria dos pais. Cabe ressaltar que na questão 17 , mesmo com a maioria dos pais optando pela resposta 5 , tem-se uma variabilidade maior nas respostas. 
Figura 5 - Frequência da Dimensão Empatia.

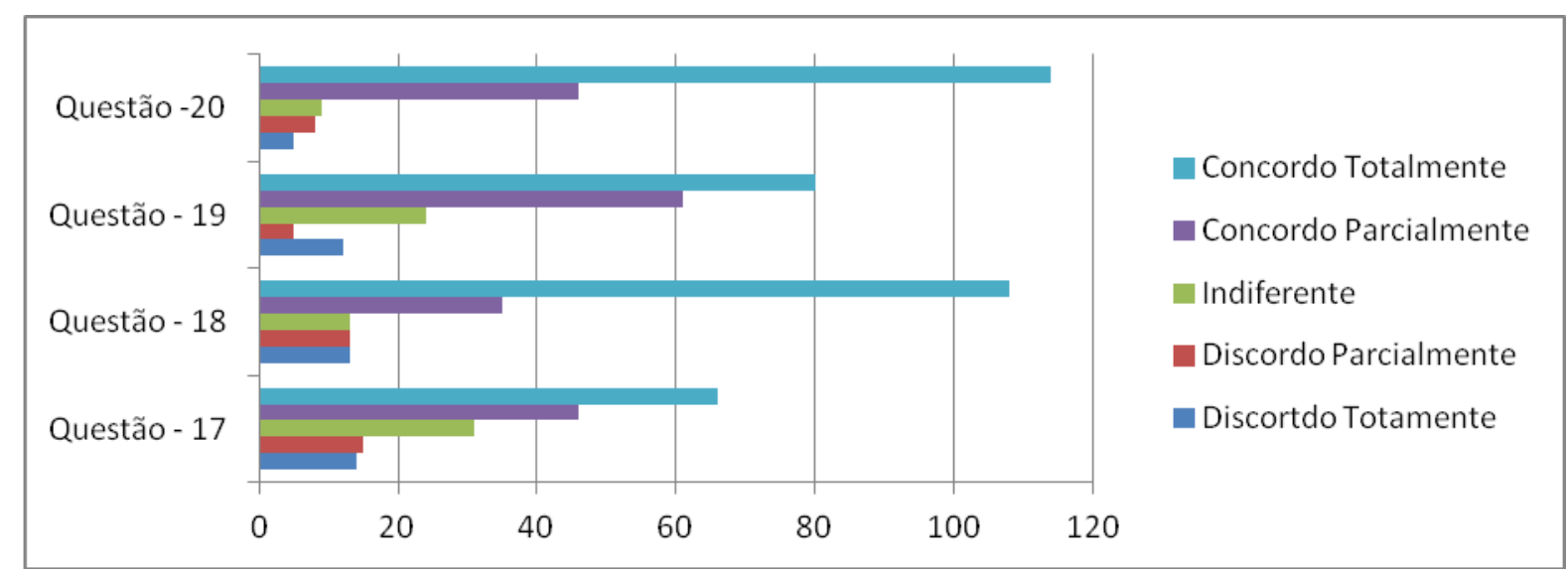

Para averiguar a confiabilidade do questionário foi calculado o Coeficiente de Cronbach para cada uma das dimensões, conforme apresentado na Tabela 3. O $\alpha$ obtido para cada uma das dimensões foi igual a 1,0, o que significa que a confiabilidade do questionário é excelente, uma vez que, o coeficiente varia entre 0 e 1 , e que quanto mais próximo de 1 , mais confiável é o questionário, garantindo que houve total compreensão dos pais dos 20 indicadores presentes no questionário.

Tabela 3 - Coeficiente de Cronbach por dimensão.

\begin{tabular}{lc}
\hline Dimensão & Coeficiente de Cronbach \\
\hline Aspectos Tangíveis & 1,0 \\
Confiabilidade & 1,0 \\
Prontidão & 1,0 \\
Segurança & 1,0 \\
Empatia & 1,0 \\
\hline
\end{tabular}

A partir dos 182 questionários que verificaram a percepção dos pais com relação à qualidade dos serviços ofertados pelos colaboradores da secretaria da escola foi possível calcular o percentual de respostas negativas, positivas e neutras que foram atribuídas para cada item (Figura 6). Foram classificadas como respostas positivas os itens assinalados nas opções 4 - Concordo Parcialmente e 5 - Concordo Totalmente; como neutra a opção 3 - Indiferente e como negativas os itens assinalados com as opções 1 - Discordo Totalmente e 2 - Discordo Parcialmente. 
Figura 6 - Classificação das Respostas para a Percepção.

\section{Classificação das Respostas Para Percepção}

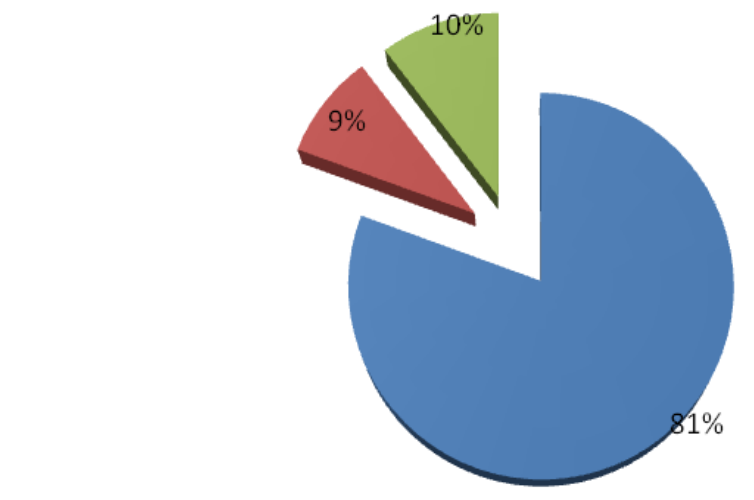

- Positivas

- Neutras

Negativas

Do total de 3.639 respostas obtidas, 2.931 (81\%) foram positivas; 329 (9\%) neutras e 379 (10\%) negativas. Com base nestes resultados pode-se concluir que as maiorias dos pais estão satisfeitos com o atendimento ofertado pelos funcionários da secretaria da instituição pesquisada. Sendo as respostas neutras e negativas um total de 19\%, em que a Equipe Administrativa deve definir estratégias e planos de ação para melhorar tais índices.

\section{Considerações Finais}

Com base nos resultados obtidos por meio da pesquisa, é possível concluir que os colaboradores da instituição ofertam um excelente serviço segundo a avaliação dos pais. Com a utilização da Escala Likert de 5 pontos, dos quais 1e 2 são considerados negativos, 3 é considerado neutro e 4 e 5 considerados positivos, $81 \%$ das respostas dos itens foram positivas, confirmando a avaliação.

Como ponto forte da pesquisa, tem-se na dimensão aspectos tangíveis, mais especificamente a localização da escola que atingiu uma média de 4,6. E nesta mesma dimensão foi detectado também o ponto crítico da escola, no item 2 que trata das instalações físicas da Escola e seus mobiliários que obteve uma média de 3,5. Mas como foi observado na análise do questionário, essa questão depende de verbas a serem liberadas pelo Governo do Estado, sendo um processo demorado.

O estudo apresentou à instituição informações importantes sobre a real percepção dos pais quanto aos serviços ofertados pelos Funcionários a Secretaria da Escola e, com essas informações a Escola pode planejar ações corretivas dos problemas encontrados. 
Espera-se que com base nos resultados apresentados pelo trabalho, a instituição elabore um Plano de Ação que venha a sanar os problemas encontrados, mesmo que isso possa levar algum tempo, visto que, a Administração local depende da Secretaria de Estado da Educação - SEED.

Uma das dificuldades encontradas durante o desenvolvimento deste trabalho foi na obtenção de questionários respondidos, o volume que retornou foi abaixo do esperado, logo a pesquisa não abarca a totalidade dos pais.

Como trabalho futuro sugere-se que após implantação de melhorias nos itens que atingiram uma média baixa na pesquisa, seja aplicado novamente a Ferramenta SERVPERF com o intuito de analisar os novos resultados alcançados sobre o nível de satisfação dos pais. Sugere-se também a aplicação da pesquisa com a utilização da Ferramenta SERVPERF em outras escolas da rede pública para verificar a correlação dos problemas entre as unidades e também as características dos problemas de cada instituição de acordo com a comunidade escolar que cada uma delas atende.

\begin{abstract}
Meeting the needs of consumers of public agencies is a very difficult task due to the unique characteristics of those services. Based on this concern, this study aims to diagnose the service quality of customer service offered by the office staff of a public school in the city of Maringá, State of Paraná. In order to assess the level of satisfaction and discover the strengths and weaknesses of the institution the tool SERPREF used to evaluate quality was used, suffering some adaptations of the original version. In data collection a questionnaire with 20 indicators was designed, divided into five dimensions of quality, that are: tangible aspects, reliability, timeliness, security and empathy. Respondents indicated their level of agreement on each aspect. The reliability of the questionnaire was identified by Cronbach coefficient, reaching excellence. The results were presented to stakeholders as the basis for decision making.
\end{abstract}

Key words: quality of services; public institution, SERVPREF.

\title{
Referências
}

COUTINHO, E. P.; MOREIRA, R T.; SOUZA, D. Aplicação do ciclo de serviços na análise da gestão da qualidade de um restaurante universitário. In: ENCONTRO NACIONAL DE ENGENHARIA DE PRODUÇÃO, 25,2005, Porto Alegre. Anais... Porto Alegre: ABEPRO, 2005.

FERREIRA, M. A. Instituições particulares de ensino superior e docência: Uma análise da qualidade da prestação de serviços e sua relação com a subjetividade do Docente. UEL, Londrina, PR, 2005.

FITZSIMMONS, J. A. Administração de Serviços: Operações, Estratégia e Tecnologia da Informação. 2. ed. Porto Alegre: Bookman, 2000.

GIANESI, I. G. N.; CORRÊA, H. L. Administração Estratégia de Serviços. São Paulo: Editora Atlas S.a, 1994.

GIL, A. C. Métodos e técnicas de pesquisa social. São Paulo: Atlas, 1999.

LAS CASAS, A. L. Qualidade Total em Serviços: conceitos, exercícios, casos práticos. 3. ed. São Paulo. Atlas, 1999. 
LONGO, R. M. J. Gestão da Qualidade: Evolução, História, Conceitos Básicos e Aplicação na Educação. Brasília: IPEA, 1996.

LOPES, C. M. Avaliação da Qualidade de Serviço: O Caso de uma Instituição de Ensino Superior. 2009.123 f. Dissertação (Mestrado em Gestão da Qualidade) - Programa de Pós-Graduação em Gestão da Qualidade, Universidade Fernando Pessoa, Fernando Pessoa, 2009.

MATTAR, F. N. Pesquisa de marketing. Edição Compacta. 3. Ed. São Paulo: Editora Atlas, 2001.

MENDES FILHO, G. A. Gestão de serviços públicos com qualidade e produtividade. Gildásio Mendes \& William Douglas. 2. ed. Niterói, Rio de Janeiro: UNIVERSO, 1997.

MIGUEL, P. A. C. Qualidade: enfoques e ferramentas. São Paulo: Artliber Editora, 2001.

NASCIMENTO, D. Analise de riscos e pontos críticos de controle (APPCC) de uma planta de processamento de alimentos (restaurante universitário) Em Ouro Preto-MG. B. CEPPA, v. 10, n. 2, p. 170-185, 1992

NORMANDO, I. M. C. Administração de Serviços Públicos com foco no cidadão: uma avaliação dos serviços prestados pelos órgãos julgadores do superior tribunal de justiça. Brasilia, UNB, 2009 - Disponível em: <http://bdjur.stj.gov.br/xmlui/bitstream/handle/2011/21225/Administracao_Servicos_Publicos_Izabely_Michelle.pdf?se quence $=1>$. Acesso em: agosto de 2011 .

PALADINI, E. P. Gestão da Qualidade: Teoria e Pratica. 2. ed. São Paulo: Editora Atlas S.A, 2006.

ROSA, P. R. S. Validando Instrumentos de Pesquisa. Capitulo 16, 2001. Disponível em: < http://www.dfi.ufms.br/prrosa/instrumentacao/Capitulo_16.pdf>. Acesso em: 10 de out. de 2011.

WALKER, D. O cliente em primeiro lugar: O atendimento e a satisfação do cliente como uma arma poderosa de fidelidade e vendas; tradução Cecília Camargo Bartalotti; revisão técnica José Augusto do Nascimento. São Paulo: Makron, 1991.

\section{Dados dos autores:}

Nome completo: Eunice Alves de Oliveira

Filiação institucional: Universidade Estadual de Maringá

Departamento: Departamento de Administração

Função ou cargo ocupado: Acadêmica do Curso de Administração - Modalidade EAD.

Endereço completo para correspondência (bairro, cidade, estado, país e CEP): Av. Colombo 5790 Jardim Universitário, Maringá - PR - Brasil - 87020-900.

Telefones para contato: (44) 30115820

e-mail: eunice_viega@hotmail.com

\section{Nome completo: Gislaine Camila Lapasini Leal}

Filiação institucional: Universidade Estadual de Maringá

Departamento: Departamento de Engenharia de Produção

Função ou cargo ocupado: Professora Assistente 
Endereço completo para correspondência: Av. Colombo 5790 - Jardim Universitário, Maringá - PR - Brasil - 87020-900.

Telefones para contato: (44) 30115820

e-mail: gclleal@uem.br

Nome completo: Francielle Cristina Fenerich

Filiação institucional: Universidade Estadual de Maringá

Departamento: Departamento de Engenharia de Produção

Função ou cargo ocupado: Professora Assistente

Endereço completo para correspondência: Av. Colombo 5790 - Jardim Universitário, Maringá - PR

- Brasil - 87020-900.

Telefones para contato: (44) 30115015

e-mail: fcfenerich@uem.br

Enviado em: 02/05/2012

Aprovado em: 09/04/2013 